\title{
LA PROTECCIÓN ESTATAL DE EDIFICIOS HISTÓRICOS. UN OBSTÁCULO A LA EMPRESARIALIDAD
}

\author{
JOAQUÍN AZPITARTE ${ }^{1}$
}

Fecha de recepción: 13 de julio de 2015.

Fecha de aceptación: 10 de junio de 2016.

Resumen: «¿Es legítima la protección estatal de edificios históricos? ¿ Debe protegerse un edificio contra la voluntad de sus propietarios? ¿ Cómo conciliar el deseo de conservación del patrimonio arquitectónico con la libertad individual y con el derecho de propiedad? ¿ ${ }^{D}$ e qué modo se manifiesta esta intervención en la actividad empresarial?

La protección estatal de edificios históricos constituye una injerencia más de la administración pública en la propiedad privada. Su aplicación condena a los propietarios al mantenimiento y conservación de sus propiedades en contra de su voluntad. Impide la transformación natural de los edificios y de la ciudad, y puede generar_importantes costes económicos para la sociedad».

Palabras Clave: Protección de edificios, Empresarialidad, Derecho de Propiedad.

Title: State protection for historic buildings: it's effect on Entrepeneurship

Abstract: «ls State-led protection of historical buildings legitimate? Should a building be protected against the will of its owners? How do we reconcile the will to preserve the architectural heritage with individual freedom and property rights? In what way does this interference of the State affect entrepreneurship? State-led protection of historical buildings represents yet another government meddling in private property. Its enforcement condemns owners to maintain and preserve their properties against their will. It prevents the natural transformation of buildings and cities and may generate significant economic costs to society.»

Key Words: Preservation, Entrepreneurship, Property Rigths.

JEL Classification: R21, R28, R31, R52

${ }^{1}$ Investigador independiente. 


\section{I \\ INTRODUCCIÓN}

La «memoria colectiva», término acuñado por el filósofo Maurice Halbwachs ${ }^{2}$, ha sido a lo largo de los últimos años, junto con otros conceptos difusos como el «interés general» ${ }^{3}$ o el «bien común», uno de los instrumentos utilizados por el Estado para defender la creciente intervención en el ámbito de lo privado. En el caso de la protección estatal de edificios, la «memoria colectiva» es la justificación a través de la cual el Estado trata de legitimar la perpetuación de inmuebles en contra de la voluntad de sus propietarios. Alrededor de esta idea ha crecido por lo tanto una gran estructura legislativa cuyo elemento principal en España es la Ley del Patrimonio Histórico Español ${ }^{4}$ que confiere a los distintos ayuntamientos la potestad para la creación de los llamados «catálogos» de inmuebles protegidos ${ }^{5}$ que obligan a los propietarios a su conservación.

La citada ley protege «los bienes muebles e inmuebles» tanto públicos como privados «considerados de interés histórico, el Patrimonio Arqueológico y el Etnográfico, los Museos, Archivos y Bibliotecas de titularidad estatal, así como el Patrimonio Documental y

2 «Lorsqu'un groupe humain vit longtemps en un emplacement adapté à ses habitudes, non seulement ses mouvements, mais ses pensées aussi se règlent sur la succession des images matérielles qui lui représentent les objets extérieurs. Supprimez, maintenant, supprimez partiellement ou modifiez dans leur direction, leur orientation, leur forme, leur aspect, ces maisons, ces rues, ces passages, ou changez seulement la place qu'ils occupent l'un par rapport à l'autre. Les pierres et les matériaux ne vous résisteront pas. Mais les groupes résisteront»«《Sans doute, cette disposition antérieure a été autrefois l'œuvre d'un groupe. Ce qu'un groupe a fait, un autre peut le défaire. Mais le dessein des hommes anciens a pris corps dans un arrangement matériel, c'està-dire dans une chose, et la force de la tradition locale lui vient de la chose, dont elle était l'image. Tant il est vrai que, par toute une partie d'eux-mêmes, les groupes imitent la passivité de la matière inerte». Halbwachs (1967)

${ }^{3}$ Constitución Española. Artículo 128: «Toda la riqueza del país en sus distintas formas y sea cual fuere su titularidad está subordinada al interés general».

${ }^{4}$ Ley 16/1985, de 25 de junio, del Patrimonio Histórico Español.

${ }^{5}$ Ley 16/1985, de 25 de junio, del Patrimonio Histórico Español. Artículo 21. «En los instrumentos de planeamiento relativos a Conjuntos Históricos se realizará la catalogación, según lo dispuesto en la legislación urbanística, de los elementos unitarios que conforman el Conjunto, tanto inmuebles edificados como espacios libres exteriores o interiores». 
Bibliográfico». Se trata por lo tanto de una legislación cuyo alcance abarca la totalidad de los bienes del territorio español sin hacer distinción entre su naturaleza privada o pública, siendo todos ellos susceptibles de ser intervenidos con importantes implicaciones para la libertad de uso por parte de sus propietarios. No obstante, esto no siempre ha sido así.

Los primeros antecedentes jurídicos de la protección de inmuebles en España los encontramos en la Cédula Real de 1803 dictada por Carlos IV «en donde por primera vez nuestro ordenamiento jurídico establece el concepto de monumento» ${ }^{6}$ y posteriormente en el decreto de 16 de diciembre de 1873 que buscaba evitar «la destrucción de un edificio público que por su mérito artístico o por su valor histórico deba considerarse como monumento digno de ser conservado» ${ }^{7}$. Esta legislación primitiva es de indudable interés por cuanto encontramos en ella un deseo de preservación del patrimonio arquitectónico junto con la voluntad de respetar la propiedad privada, ciñendo así su ámbito de actuación a los bienes de titularidad pública.

Y es que en palabras de Juan Manuel Becerra García lo «que caracteriza a la legislación española de patrimonio histórico», en 1873, "es el respeto a la propiedad privada sancionada como institución sagrada e inviolable por el Código de Napoleón y el surgimiento del Estado Liberal que perdurará hasta la conclusión de la primera guerra mundial. Esta concepción romanista del derecho privado limita la acción del estado prácticamente a los bienes de titularidad pública» ${ }^{8}$. Como tendremos la oportunidad de ver el escenario ha cambiado de forma notable. Ya no son sólo los bienes públicos los susceptibles de ser protegidos sino que el Estado, en ese afán expansivo que lo caracteriza, ha afectado todos aquellos bienes privados que ha considera oportuno, generando así importantes ineficiencias económicas y no pocas injusticias. Tampoco este fenómeno es exclusivo de nuestro país. En el primer caso expuesto en este trabajo observaremos como una ciudad con un espíritu tan dinámico como es la de Nueva York se ha visto afectada en los últimos años por esta fiebre proteccionista y paralizante.

\footnotetext{
${ }^{6}$ Becerra García, J. M. (1999)

7 Becerra García, J. M. (1999)

8 Becerra García, J. M. (1999)
} 


\section{II \\ LA PROTECCIÓN VOLUNTARIA DE EDIFICIOS}

La protección y conservación voluntaria de un edifico es un hecho sin duda loable. Las características históricas, estéticas, o monumentales de un bien pueden merecer por parte de su propietario el deseo de conservarlo y protegerlo. Esta decisión, implica la renuncia voluntaria al uso alternativo del terreno en el que se asienta en favor de su conservación. En estos casos la valoración subjetiva del bien, no necesariamente monetaria, es superior a la de cualquier transformación alternativa. Varios factores entran en juego en el cálculo del propietario cuando decide si es deseable o no la conservación de un bien inmueble: la percepción subjetiva de su valor, la percepción subjetiva del valor de los usos alternativos del suelo que ocupa y la percepción subjetiva del valor de cualquier transformación posible. Todos estos factores permiten que el propietario realice el cálculo económico necesario para tomar la decisión final.

\section{III \\ LA PROTECCIÓN DE EDIFICIOS IMPUESTA Y LA IMPOSIBILIDAD DEL CÁLCULO ECONÓMICO}

El panorama sin embargo cambia cuando lo que se quiere proteger es la propiedad ajena. Es decir, cuando el Estado debe decidir que bienes son susceptibles de conservarse y cuáles no. Si bien, en un primer momento, pudiera parecer que imponer la protección de un edificio valioso es siempre una medida positiva, después de un análisis pormenorizado observamos que no es así.

La protección del patrimonio arquitectónico por parte del Estado adolece de la imposibilidad del cálculo económico9 ${ }^{9}$ La ad-

\footnotetext{
9 «Este problema económico fundamental era básicamente un problema teórico de dinámica económica, que planteaba la imposibilidad de efectuar el cálculo económico en ausencia de un proceso de mercado movido por la empresarialidad por ser este el único que continuamente da lugar a que los agentes económicos descubran la información práctica y dispersa que es necesaria para efectuar estimaciones prospectivas sobre costes y beneficios». Huerta de Soto (2010), p. 227.
} 
ministración pública tiene serias dificultades para discernir si «compensa» o no proteger un determinado inmueble, es decir, si las ganancias derivadas de la protección son mayores que los costes que esta protección conlleva. Parece claro que proteger conjuntos arquitectónicos de gran relevancia histórico-artística como es el casco antiguo de Venecia aporta, finalmente, mayores beneficios a sus ciudadanos que los costes derivados de su mantenimiento. Sin embargo, este cálculo no es en absoluto evidente, y lo es menos aún en el caso de inmuebles menos singulares. Sería necesaria la propiedad privada del bien inmueble a evaluar y disponer de un sistema de formación libre de precios para obtener la información precisa para evaluar los costes y los beneficios de la conservación del mismo.

Sin embargo, tras la catalogación de un inmueble, el Estado condena en muchos casos a los propietarios a una situación de ineficiente uso de su patrimonio. La protección de un edificio histórico supone limitaciones importantes en su aprovechamiento por parte de los propietarios. Estas limitaciones varían dependiendo del nivel de protección del inmueble: protección integral de todo el edificio, que no permite ninguna alteración del inmueble, protección ambiental que exige preservar la fachada, protección parcial que protege los elementos que caracterizan al edificio, etc. Todos estos niveles de protección obligan, en mayor o menor medida, a asumir unos costes extra de mantenimiento e incluso en forma de lucros cesantes por imposibilidad de transformación y aprovechamiento del inmueble. Se da además la circunstancia de que la protección coactiva de un inmueble produce una asimetría entre aquellos que disfrutan contemplando el singular edificio y aquellos que deben soportar la carga de su mantenimiento. Los beneficiados son personas ajenas al inmueble que disfrutan de la belleza del edificio, mientras que los que soportan las cargas de los costes son los propietarios, que no reciben compensación alguna. Es, por ejemplo, el caso de los comerciantes que tienen como clientes a los turistas de ciudades monumentales que ven aumentar sus ventas gracias a los inmuebles que mantienen otros. De modo que otro de los defectos del sistema actual de protección de edificios es que, el obligado a preservar, no sólo debe asumir los costes del mantenimiento del edificio y renuncia al lucro que le reporta- 
ría su ampliación o transformación, sino que tiene importantes dificultades para aprovechar los beneficios surgidos de la protección. La solución contractual o empresarial se presenta como la única solución viable en la que los propietarios puedan internalizar los beneficios.

Por otro lado, la protección de un edificio sin el libre consentimiento de su propietario es una práctica a nuestro juicio inaceptable y un abuso de poder por parte de la administración pública que utiliza todo su aparato de coacción para doblegar la voluntad de los legítimos propietarios.

La protección de edificios se convierte para el dueño en una losa de la que difícilmente podrá deshacerse, quedando maniatado para acometer futuras actuaciones y sometidos a unos costes que no encontrarán contrapartida económica que los compense. Este perjuicio, que en un principio es solo individual, acaba siéndolo también social cuando se expande sin control. Al generalizarse la protección, se inicia el bloqueo de muchos de los activos de la ciudad, dificultando su transformación, el aprovechamiento de sus recursos y el mantenimiento de su vitalidad.

De modo que algunas de las consecuencias para el propietario afectado por la protección central son las siguientes: la necesidad de asumir mayores costes de mantenimiento del inmueble derivados de las mayores y singulares necesidades de los edificios antiguos, obligación de vivir en un inmueble obsoleto material y funcionalmente, imposibilidad o limitación para realizar las transformaciones necesarias o deseadas del inmueble, imposibilidad de demolición del edificio para la construcción de uno nuevo, imposibilidad o limitación para desarrollar determinadas actividades en el interior del edificio debido a las limitaciones formales del edificio protegido o a limitaciones legales derivadas de la protección, dificultad de venta del inmueble precisamente debido a las restricciones a las que está sujeto.

Podemos concluir por lo tanto que la protección de inmuebles por parte de la administración supone una injerencia del Estado en la propiedad privada al imponer el estatus legal de "protegido» a cualquier inmueble sin necesidad de aprobación previa por parte de sus dueños y sin posibilidad de evaluar la conveniencia o no de la protección. 
IV

\section{LA PROTECCIÓN MASIVA DE EDIFICIOS}

La protección central de inmuebles conduce en una segunda instancia a una sobreprotección cuantitativa y cualitativa de inmuebles. Se trata de un problema que viene afectando a muchas de las ciudades de los llamados países desarrollados en los últimos años y de manera creciente. Movidos por ese afán de proteccionismo desmesurado, y sin legitimidad ni posibilidad de hacer los cálculos económicos necesarios, la administración pública protege de forma compulsiva todo tipo de inmuebles en busca de la preservación de la «identidad» de la ciudad. Sin embargo, como veremos, la identidad de la ciudad no es algo estático y tangible que deba conservarse, sino que es el fruto dinámico de la empresarialidad humana.

Llevados por un romanticismo extremo, los funcionarios quieren conservar la ciudad tal y como era en el pasado sin ser conscientes de que, lo arquitectónico, finalmente, y como toda belleza, es necesariamente efímero, y que la búsqueda de una protección indiscriminada y artificial de los edificios acaba consiguiendo una ciudad de "cartón piedra» con serias y negativas disfuncionalidades económicas. Sin esta protección indiscriminada estatal, bellos edificios desaparecerían pero otros nuevos nacerían. Es la naturaleza cambiante de la ciudad, la destrucción creativa schumpeteriana y el precio a pagar por la prosperidad y el desarrollo. No podemos convertirnos en obsesivos proteccionistas. Debemos ser selectivos con aquello que queremos conservar y esto sólo puede conseguirse mediante la adquisición privada de los inmuebles.

Por lo tanto, algunas de las consecuencias sociales derivadas de la protección masiva de edificios son las de crear ciudades paralizadas en el tiempo, ciudades de "cartón piedra» alejadas de la realidad actual, ciudades en las que la dinámica económica se ve seriamente afectada, ciudades en las que es difícil materializar el ahorro o ciudades con viviendas y locales obsoletos.

Como veremos en la siguiente sección la ciudad de Nueva York se ha caracterizado a lo largo de la historia por su vitalidad y emprendimiento. Ese es su verdadero carácter. Cualquier medida coercitiva, impuesta sobre la voluntad de los propietarios, no hace 
sino impedir su desarrollo y el descubrimiento y creación de nuevas y maravillosas formas arquitectónicas y urbanas. La protección es legítima desde la propiedad y sólo desde esta se logrará el equilibrio necesario para que se ponga en marcha el complejo mecanismo social. EN MANHATTAN.

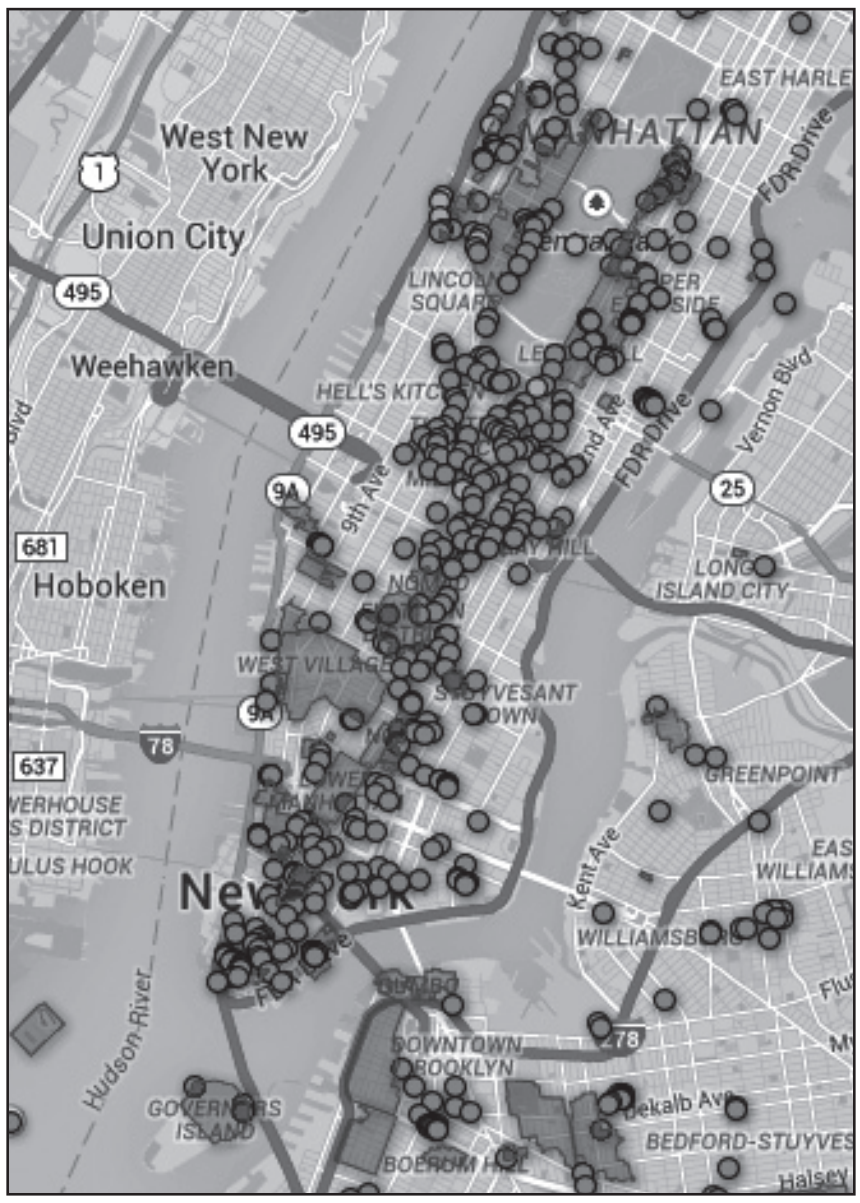

Fuente: Landmarks Preservation Commission 
$\mathrm{V}$

\section{EL CASO DE MANHATTAN}

En un principio y a los ojos del lector ajeno a la realidad legal de Nueva York, pudiera parecer que Manhattan es uno de los paradigmas de la libertad edificatoria. Esa es la idea que al menos muchos tienen al contemplar las imágenes de la ciudad de los rascacielos. Nada más lejos de la realidad. Manhattan es actualmente una metrópoli que en muchos de sus barrios está anclada en el tiempo. Algunos de sus edificios son antiguas reliquias del pasado y, si bien la ciudad disfruta todavía de zonas en las que emergen nuevos y espectaculares rascacielos, ha perdido gran parte de su dinamismo e intensidad. Las ciudades asiáticas han tomado la delantera en vanguardia edificatoria y vitalidad. Para conocer algunas de las razones de la situación actual debemos remontarnos a los años 60 .

En 1963, los propietarios de la estación de tren de Pensilvania situada en la confluencia de la calle 33 y la séptima avenida, procedieron a la demolición del emblemático edificio que la acogía y a la posterior venta del solar para darle, a los terrenos, un nuevo destino. En ellos se asentarían el actual Madison Square Garden, pasando la nueva estación de tren a ser subterránea. Además de acabar con un excepcional edificio esta iniciativa empresarial puso indirectamente en marcha una legislación local en materia de protección de inmuebles que desde entonces no ha dejado de crecer hasta alcanzar dimensiones verdaderamente invasivas. Según Edward L. Glaeser en un artículo de $2010^{10}$, «sin contar los parques, el sur de Manhattan contiene alrededor de 7.700 hectáreas de superficie potencialmente edificable. Hoy en día, casi el 16 por ciento de estos terrenos está en los distritos históricos y por lo tanto sujetos a la autoridad de la comisión». No es la primera vez que a partir de una loable iniciativa se acaba logrando un perjuicio generalizado. 
ILUSTRACIÓN 2: ANTIGUA ESTACIÓN DE PENSILVANIA EN LA CIUDAD DE NUEVA YORK.

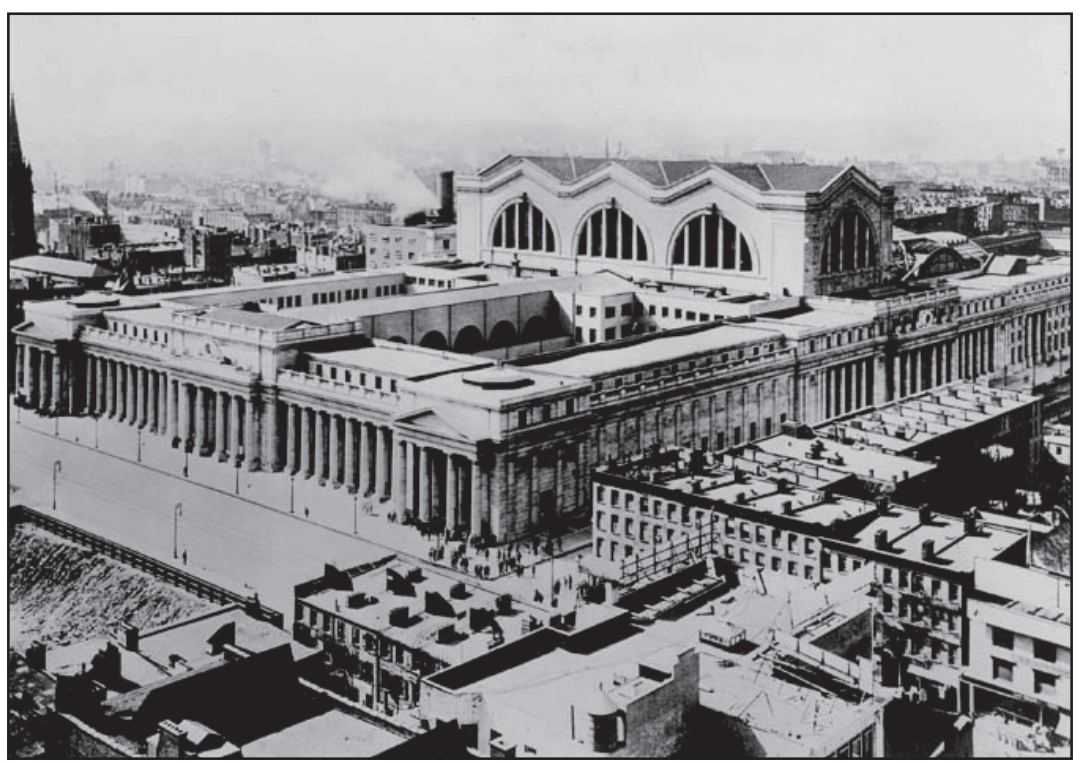

Fuente: Landmarks Preservation Commission

VI

\section{EL PROBLEMA DE LA LEGITIMIDAD Y EL ESPÍRITU DE LA CIUDAD}

En Nueva York, el organismo encargado de la protección y catalogación de inmuebles es la Landmark Preservation Comission. Organismo creado en 1965 con una aparentemente encomiable intención: «Conservar los barrios históricamente significativos es importante para los neoyorquinos de hoy y para las futuras generaciones, de manera que conozcan su herencia cultura $l \gg^{11}$. Sin em-

11 «Preserving historically significant neighborhoods is important fortoday's New Yorkers, and for future generations, to understand their cultural heritage». Aprobación de Ridgewood Central como distrito histórico de Nueva York. 9 de diciembre de 2014. Landmarks Preservation Commission. 
bargo, actualmente «hay más de 33.000 propiedades protegidas en Nueva York» ${ }^{12}$ en un auténtico ejercicio de sobreprotección. La Landamark Comission está compuesta por un «panel de 11 comisarios nombrados por el alcalde con el apoyo de un personal de aproximadamente 67 conservacionistas, investigadores, arquitectos, historiadores, abogados, arqueólogos y empleados administrativos» ${ }^{13}$

Los conservacionistas han conseguido que parte de Nueva York sea una reliquia de su pasado, sin la vida que caracteriza a las ciudades que carecen de obstáculos para desarrollarse. Obstinados en mantener la estética de un tiempo pasado, impiden que los propietarios sigan creando la ciudad tal y como lo hicieron sus antepasados. Una ciudad espontánea, cuyo producto han fascinando a los burócratas, ahora se ve condenada a la ausencia de espontaneidad porque esos mismos funcionarios lo impiden en una contradicción insalvable $¿ \mathrm{O}$ acaso es entendible que los políticos y funcionarios no permitan que la ciudad siga desarrollándose por los medios que ellos mismo reconocen que tan buenos resultados han dado? Y más profundamente aún ¿Son ellos las personas adecuadas para decidir en que momento debe detenerse la transformación de la ciudad y su evolución? Por otro lado ¿El criterio para proteger inmuebles debe ser el de una comisión de 11 personas ajenas a los problemas económicos que supone dicha protección? ¿Hubiera sido razonable proteger todas las primeras casas de estética holandesa del entonces New Amsterdam porque formaban parte de la historia de la ciudad y seguir protegiendo masivamente las construcciones futuras? En todo caso, un equilibrio debe imponerse en los criterios de protección y ese equilibrio lo da necesariamente la propiedad privada de los mismos o los acuerdos voluntarios entre las partes.

Así pues, además del obstáculo del cálculo económico, nos hallamos frente al problema añadido de la legitimidad de estas

12 "There are more than 33,000 landmark properties in New York City». About the Landmarks Preservation Commission. http://www.nyc.gov/html/lpc/html/about/about. shtml

13 «The agency is comprised of a panel of 11 commissioners who are appointed by the Mayor and supported by a staff of approximately 67 preservationists, researchers, architects, historians, attorneys, archaeologists and administrative employees». About the Landmarks Preservation Commission. http://www.nyc.gov/html/lpc/html/about/about.shtml 
protecciones que nos lleva a hacernos las siguientes preguntas: ¿Es legítimo proteger estos inmuebles en contra de la voluntad de sus propietarios? Si estos inmuebles surgieron fruto de la espontaneidad, la creatividad y el emprendimiento ¿es adecuado bloquear esa espontaneidad, creatividad e iniciativas empresariales inmovilizando tal número de edificios? Según la doctrina misesiana ${ }^{14}$ el Estado debe velar por la protección de la propiedad en el sentido de proteger la soberanía del individuo sobre su propiedad. Sin embargo la legislación actual, desvirtuando las funciones originarias del Estado, habilita a este para impedir el uso libre de la propiedad.

Uno de los argumentos empleados por los departamentos de protección de inmuebles es el de que es necesario preservar «el espíritu de la ciudad», variante activa de la «memoria colectiva». Pero el espíritu de la ciudad es precisamente aquel que le confieren los habitantes de la ciudad con su actuar y por lo tanto necesariamente debe estar unido a la transformación de la ciudad y no a su parálisis ¿Logramos conservar el espíritu de la ciudad aferrándonos a su pasado o lo lograremos conservando esa vitalidad y diversidad que le es propia como en el caso de Nueva York? ¿No debemos asumir que la ciudad es un ente en permanente transformación y no caer en la tentación de vivir en el recuerdo? ¿No surgirán nuevos y relevantes edificios de ulteriores transformaciones tal y como lo hicieron nuestros antepasados? Con todas estas preguntas no estamos cuestionándonos la conveniencia o no de la protección de inmuebles. Sino que tratamos de mostrar que la protección de inmuebles centralizada con su tendencia a la expansión indiscriminada genera innumerables problemas para los propietarios y para la dinámica de la ciudad.

La Landmark Preservation Commission se dedica desde los años 60 a «distinguir» a algunos edificios con la designación de «Individual Landmark». Esta decisión condena en muchos casos al edificio a la obsolescencia y al propietario a la pérdida de importantes ganancias $y$, a medida que se ha ido diseminando, a la ciudad a la

${ }^{14}$ «El liberalismo asigna al Estado la tarea de proteger la vida, la salud, la libertad y la propiedad de sus ciudadanos contra la agresión violenta o fraudulenta». Mises (2002), p. 83. 
pérdida de su vitalidad para acabar siendo un de museo de su pasado, sin la esencia dinámica de las ciudades libres.

VII

\section{LOS ARGUMENTOS PARA LA PROTECCIÓN Y LAS CONSECUENCIAS DE LA SOBRE PROTECCIÓN}

La Landmark Preservation Commission formada por 11 personas se reúne periódicamente para decidir qué hacer con las hermosas propiedades de otros y, termina, al cabo de los años, en ese estado en el que acaban muchas personas que acumulan cosas sin control. En lo que podría ser una variación administrativa del llamado Trastorno de Acumulación Compulsiva ${ }^{15}$ el gobierno de Nueva York alcanza ya las citadas de 33 mil propiedades protegidas. Un resultado inevitable cuando se otorga la capacidad de catalogación de inmuebles a una comisión que no debe asumir coste alguno en la toma de sus decisiones.

$Y$ es que, cual coleccionista fuera de control, quien no utiliza sus propios recursos para decidir que objetos son dignos de preservación, no conoce el coste de hacerlo y tiene por lo tanto serias posibilidades de excederse en el número de inmuebles catalogados. A modo de ejemplo a continuación citamos una justificación cualquiera de la catalogación de un barrio entero en Manhattan:

«La Landmarks Preservation Commission de Nueva York ha aprobado hoy por unanimidad la designación del 990-building Central Ridgewood Historic District in Queens. El nuevo barrio se compone principalmente de casas adosadas de ladrillo, y representa uno de los enclaves más armoniosos y arquitectónicamente distinguidos de viviendas obreras construidas en la ciudad de Nueva York a principios del XX» ${ }^{16}$.

15 «El síndrome de acaparador compulsivo, también conocido como síndrome de acumulación compulsiva, trastorno por acumulación o disposofobial es un trastorno psicológico caracterizado por la tendencia a la acumulación de artículos u objetos (implicando la incapacidad para deshacerse de ellos) en forma excesiva en referencia a cantidades socialmente aceptadas». https://es.wikipedia.org/wiki/S\%C3\%ADndrome_de_ acaparador_compulsivo

16 «The New York City Landmarks Preservation Commission today unanimously approved the designation of the 990-building Central Ridgewood Historic District in 
De manera que, porque un edificio es antiguo, de ladrillo, armónico y acogió a trabajadores, debe ser preservado bajo amenaza de multa a sus propietarios que nada podrán hacer sin consultar a la comisión pertinente que, sobra decirlo, no permitirá modificación alguna de su aspecto exterior. Esta decisión bloqueará toda posibilidad de construir en el lugar cualquier otro edificio alternativo, ya sea centro comercial o rascacielos, a pesar de que sus propietarios hayan detectado oportunidades de ganancia y, por lo tanto, necesidades que satisfacer para la sociedad. No dudamos de la armoniosa estética del edificio ni de su belleza. Sino que consideramos que estas cualidades son bastante habituales en los edificios y que, a falta de otros criterios que incluyan el cálculo económico, la comisión acabará protegiendo masivamente edificios en la ciudad como así está ocurriendo.

Una vez adoptada la decisión de proteger un edificio es usual observar que el resultado obtenido es el contrario al buscado. Inmuebles en estado de abandono porque han perdido la posibilidad de adaptarse a las nuevas circunstancias. La protección central, incapaz de encontrar el equilibrio entre protección y las nuevas necesidades que marca el tiempo, imposibilita toda posibilidad de adaptación a nuevos usos y condena el edificio a su obsolescencia o incluso destrucción ${ }^{17}$. Este deterioro paulatino es producido por la inacción del propietario que, al verse imposibilitado de utilizar

\footnotetext{
Queens. The new district mostly consists of brick row houses, and represents one of the most harmonious and architecturally-distinguished enclaves of working-class dwellings built in New York City during the early twentieth century». Aprobación de Ridgewood Central como distrito histórico de Nueva York. 9 de diciembre de 2014. Landmarks Preservation Commission.

${ }^{17}$ Los ejemplos de deterioro de inmuebles protegidos son innumerables. Este es el caso de la ciudad de La Coruña. «La declaración de ruina del edificio modernista situado en el número 152 de General Sanjurjo abrió de nuevo hace unos días el debate sobre la conservación de los inmuebles protegidos en la ciudad. Junto con agresiones puntuales, el patrimonio arquitectónico de la ciudad ha venido sufriendo en las últimas décadas un deterioro progresivo que ha derivado en la declaración de ruina de 68 edificios protegidos en el casco histórico». «Desde que hay registro el Ayuntamiento se ha estudiado el deterioro de 74 edificios catalogados en la zona afectada por el Plan Especial de Protección y Reforma Interior de Ciudad Vieja y Pescadería (Pepri). De ellos, 68 fueron declarados finalmente en ruina». La Voz de Galicia. (2012). http:// www.lavozdegalicia.es/noticia/coruna/2012/02/19/once-68-edificios-catalogados-declarados-ruina-fueron-demolidos/0003_201202H19C2994.htm
} 
el inmueble según su criterio, renuncia a su uso o incluso, en algunas ocasiones, procede a la destrucción activa de su propiedad en una muestra palpable de su desesperación ${ }^{18}$.

Una de las soluciones adoptadas por el gobierno municipal de Nueva York para no perjudicar a los propietarios de los inmuebles protegidos es que estos puedan vender su $\mathrm{FAR}^{19}$ a otras propiedades. Con ello pretende conseguirse que el propietario afectado por la protección no sufra el lucro cesante que supone la imposibilidad de ampliación del edificio, viéndose compensado económicamente por aquel vecino que decida materializar el FAR no utilizado. Sin embargo, esta solución, aparentemente benigna e ingeniosa, no lo es tanto si vemos sus posteriores consecuencias. A través de este mecanismo son los propietarios de los inmuebles no catalogados que quieren construir en altura los que de facto sufragan la protección. El resultado del proceso es, por un lado, un inmueble protegido en base a unos dudosos criterios e incapaz de adaptarse a nuevas soluciones empresariales, y un nuevo edificio que, en el mejor de los casos, ha tenido que soportar unos incrementos de costes que no le correspondían. Y digo en el mejor de los casos porque en muchos otros esos costes añadidos serán suficientes para hacer inviable su construcción o ampliación ${ }^{20}$. Yendo más allá, el aumento de los costes del nuevo inmueble supondrá a largo plazo un aumento de los precios de la vivienda y demás productos urbanos, por cuanto estos costes son susceptibles de ser transmitidos directamente al precio final o por cuanto suponen una merma en los

18 También los casos que muestran la desesperación de los propietarios son abundantes. Este caso de la ciudad de Madrid sirve como ilustración: «Gracias al aviso de un ciudadano y socio de McyP hemos tenido noticia del derribo que se está llevando a cabo, durante estos días festivos, de un edificio protegido con Nivel 3 (conservación de la fachada) en la confluencia de la calle Alfonso XII y el Paseo de la Infanta Isabel. En una ubicación inmejorable, junto a la estación de Atocha, y tras varios intentos anteriores en los que no tuvieron éxito, por fin lo han conseguido: El edificio está siendo derribado tras años de abandono y un deterioro buscado». Madrid, Ciudadanía y Patrimonio. (2014). http://madridciudadaniaypatrimonio.org/node/556

19 FAR: Floor Area Ratio. Concepto similar al de Edificabilidad en España. Es decir, número de metros cuadrados que son edificables por cada metro cuadrado de parcela.

20 «La diferente utilización de los factores limita la cantidad disponible para cualquier tipo de producción, de tal suerte que el valor del producto no puede ser inferior al valor conjunto de todos los factores utilizados de forma concurrente para su producción». HAYEK (2002) 
márgenes de beneficio y por lo tanto en las posibilidades de que se amplíe la competencia.

Nueva York tiene un importante problema de vivienda. La protección masiva de inmuebles, apuntalada por una restrictiva zonificación, condenan a una limitación artificial de los recursos disponibles que contribuyen a limitar la oferta y a aumentar su precio. Este hiperproteccionismo en el urbanismo es la sublimación del intervencionismo económico por parte del Estado

Hay que pensar que no todo inmueble vale para toda actividad. Los inmuebles deben tener estructuras, distribuciones y tamaños adecuados a la actividad que desean albergar. Impedir la transformación de los edificios y mantener su configuración actual es dar por hecho que los ciudadanos de ese barrio no van a necesitar nuevos servicios ni nuevas soluciones empresariales. Muchos de estos inmuebles están abocados a contar con actividades de poco valor y escasa capitalización. Espacios más capitalizados en muchas ocasiones requieren de mayores superficies y de nuevas soluciones constructivas y, por lo tanto, la imposible transformación de los edificios supone una barrera a la prosperidad de los barrios. Muchas de estas potenciales transformaciones urbanas no llegan a materializarse sin que quede constancia en lugar alguno el intento frustrado.

Cuidar y mantener el inmueble existente, creado, construido o comprado, es de suma importancia para su propietario. El edificio es el ahorro en forma de activo inmobiliario. Su destrucción es la destrucción de su riqueza. Por eso quien decide transformar o demoler un inmueble toma una decisión que en si misma es compleja. El propietario debe vencer la dificultad de enfrentar incertidumbres futuras. Podemos decir que un edificio que ya existe, tiene una importante inercia a seguir existiendo, a permanecer. La decisión de la transformación o demolición del inmueble es puramente empresarial y es movida por la detección de ganancias resultantes de satisfacer las necesidades del resto de ciudadanos. Su bloqueo supone la posibilidad de dejar insatisfechas estas necesidades sociales e individuales, e impide que el proceso dinámico de búsqueda constante del equilibrio social se realice eficientemente. En esta línea hay que pensar que cada vez que se hace efectiva una de estas normas, esto es, que un empresario se vea impo- 
sibilitado de satisfacer su deseo de transformar o demoler su edificio para emprender un nuevo proyecto empresarial, una coordinación social se ha visto frustrada. En su conjunto, las coordinaciones sociales fallidas dificultan el trabajo de coordinación social entre los individuos.

Los edificios protegidos se encuentran en Nueva York por toda la ciudad. Cada uno de ellos supone un bloqueo de la acción empresarial y la imposibilidad de que en ellos se materialicen las adecuadas soluciones que compensen los desequilibrios sociales.

\section{VIII LA BUROCRACIA}

A todas estas medidas paralizantes de la actividad empresarial hay que añadir todas aquellas destinadas al control para el cumplimiento de las normas de protección. El reducido margen de actuación permitido en los inmuebles requiere de un proceso burocrático altamente desincentivador. Las decisiones empresariales suponen un riesgo de tiempo y de dinero para el que las toma. Son auténticas aventuras en las que el emprendedor busca una ganancia surgida de satisfacer una necesidad ajena o propia. Cualquiera de ellas tiene en su coste de oportunidad el más exacto reflejo de su valor. De tal manera que ante un obstáculo añadido a su deseo de mejorar el edificio, el empresario sencillamente, y en muchos de los casos, optará por emprender otro plan alternativo más beneficioso para él.

IX

SOLUCIONES PROPUESTAS. COMPRAR PARA PROTEGER

Algunas de las soluciones existentes en la actualidad y que permiten paliar en alguna medida el mal causado no están suficientemente extendidas ni tampoco las consideramos como óptimas. La compensación del lucro cesante puede realizarse mediante la venta de la edificabilidad no consumida tal y como se hace en Nueva 
York con el FAR. Aplicando esta técnica los propietarios del barrio del Albaicín en Granada no tendrían que soportar el lucro cesante de la conservación de sus viviendas ya que podrían vender aquella edificabilidad que no pueden consumir para que otros la materialicen en otros barrios. Sin embargo, esta solución termina por ser ineficiente dado que las cargas se transmiten a otros propietarios al tener que comprar edificabilidad tal y como se ha explicado a lo largo del artículo. La compensación de impuesto municipales es otra forma de compensar los perjuicios de los propietarios de los edificios protegidos que se ven obligados pagar un sobrecoste para su mantenimiento. Sin embargo, nada de todo esto acaba con el núcleo del problema que es la protección indiscriminada contra la voluntad de los propietarios y sin posibilidad de hacer el cálculo económico.

Cuando uno no es propietario de algo la percepción sobre el fin adecuado de edificio está fuertemente distorsionada. Esta percepción, sin embargo, cambia ipso facto cuando uno se convierte en dueño del inmueble. Los criterios de viabilidad se manifiestan con toda claridad y se imponen necesariamente frente a la incompleta percepción del problema que ofrece la visión funcionarial. La administración pública solo percibe parte del problema objeto de estudio. Depositando la labor de protección en manos del Estado, la catalogación de edificios se convierte en un juego perverso en el que poco importan la viabilidad económica y funcional del inmueble. En la balanza solo gravitan aspectos artísticos e históricos que, en ausencia de contrapesos, necesariamente se inclinarán hacia la protección y el inmovilismo.

La única forma de poder abordar, con toda la información necesaria, la necesidad o no de la protección de un edificio y la intensidad con la que se lleva a cabo es desde la propiedad de esta. La protección de edificios no solo es un problema monetario, ni artístico, ni cultural ni de percepción subjetiva sino que es una conjunción de todos ellos solo perceptible desde la propiedad y solo legitimada por esta. Una asociación puede promover la conservación de un inmueble dado que proporciona beneficios culturales y sociales innegables. Pero esa apreciación subjetiva debe realizarse a través de la adquisición del mismo. El que quiera conservar algo debe adquirirlo sin coacción. Las sesgadas y ligeras apreciaciones 
de quien no es propietario adolecen necesariamente de la imposibilidad de un análisis coste-beneficio adecuado y tenderán inevitablemente a una sobre protección tanto en cantidad como en intensidad

Hay gente que tiene especial apego a algunos edificios de la ciudad. Se escandalizan cuando uno de esos edificios es demolido y exigen que el gobierno imponga una ley para la conservación de inmuebles. Así nació la mencionada Landmarks Preservation Commission de Nueva York. Sin embargo, las personas que presionaron para la creación de este organismo muy bien podrían haber creado una asociación privada de protección. Los deseos de protección no pueden imponerse y sufragarse con dinero ajeno. Sociedades privadas de protección de edificios en las que los socios sean amantes de la conservación del pasado o adquisición por parte de fundaciones son una adecuada solución. Asociaciones sin ánimo de lucro o de aquellas que busquen un beneficio monetario por la explotación de aquello que protegen. De esta forma podrá valorarse si es adecuada o no la protección de determinados edificios y podrá innovarse en la búsqueda de nuevas soluciones empresariales ¿Y cuál es el papel de la administración? Desde una visión liberal, la administración pública no debe tener en ningún caso potestad en este ámbito más allá de la catalogación de sus propios activos inmobiliarios destinados a las labores administrativas que le son propias. Un mal menor, para la transición a un sistema de protección de libre mercado, es la protección estatal de edificios de evidente interés histórico y artístico siempre que se realice a través de la compra venta voluntaria del inmueble y nunca de la acción coactiva sobre el propietario. El procedimiento de compra para proteger por parte de la administración favorece cierta discriminación y una valoración que, aunque más imperfecta que la privada, permitirá percibir en parte del coste de la decisión. La libertad de usos y una mayor flexibilidad en las posibilidades de transformación de los inmuebles son también pasos intermedios deseables aunque en ningún caso definitivos. 


\section{$X$ \\ CONCLUSIONES}

(1) La protección estatal de edificios supone una injerencia del Estado sobre la propiedad privada y un bloqueo de los recursos disponibles en la ciudad. Aboca de esta forma a un encarecimiento de los productos urbanos resultantes. Su puesta en marcha debe evaluarse por lo tanto con mucha atención observando criterios económicos que solo pueden lograrse eficientemente a través de la propiedad del inmueble.

(2) La protección de inmuebles por parte de la administración pública y su imposibilidad de cálculo económico originan una tendencia a la sobreprotección que a su vez supone un empobrecimiento de la ciudad y un impedimento a su desarrollo y transformación.

(3) La solución propuesta pasa por adquirir sin coacción aquello que se quiera proteger. Los sentimientos de protección no pueden imponerse y sufragarse con dinero ajeno. Sociedades privadas de protección de edificios en las que los socios sean amantes de la conservación del pasado son una adecuada solución.

(4) Entendemos que toda solución estatal a la protección de inmuebles tiene que pasar por el acuerdo contractual, explícito y voluntario, con los actuales propietarios. El Estado debe evaluar la protección de los inmuebles haciéndola compatible con la viabilidad funcional y económica de los mismos.

\section{REFERENCIAS BIBLIOGRÁFICAS}

ANDerson, T.L. y Leal, D.R (1993): Ecología de mercado. Madrid. Unión Editorial

ANDERson, D.E. y Moroni, S. (2014): Cities and private planning. Massachusetts. Edward Elgar Publishing.

BAstiat, F. (2005): La Ley. Madrid. Alianza Editorial.

BECERRA GARCÍA, J. M. (1999): «La legislación española sobre patrimonio histórico, origen y antecedentes. La ley de Patrimonio histórico andaluz». V Jornadas sobre Historia de Marchena. El Patrimonio y su Conversión. 
BLock, W. (2002): Derecho de propiedad privada, interpretaciones erróneas, moralidad y economía: En respuesta a Demsetz. Buenos Aires. Revista Libertas. Instituto Universitario Eseade.

CAmagni, R. (2005): Economía Urbana. Barcelona. Antoni Bosch

GHersi, E. (2014): Conferencia: Mercado informal desde el Análisis Económico del Derecho. Universidad Francisco Marroquin. [https://www.youtube.com/watch?v=jBOYCoHlOfE\&feature =youtu.be]

Glaeser, E.L. (2010): «Preservation Follies», City Journal

Halbwachs, M. (1967): La Mémoire Collective. Paris. Les Presses universitaires de France. [ $2^{\mathrm{a}}$ edición]

HAYEK, F. vON (1997): Introducción de los Principios de Economía Política de Carl Menger. Madrid. Unión Editorial. [2a edición]

- (2006): Derecho, Legislación y Libertad. Madrid. Unión Editorial.

- (2008): Los Fundamentos de la Libertad. Madrid. Unión Editorial. [8 $8^{\mathrm{a}}$ edición]

- (2009): Individualismo: el verdadero y el falso. Madrid. Unión Editorial.

- (2010): La Fatal Arrogancia. Madrid. Unión Editorial. [3 $3^{a}$ edición]

HuERTA DE SOTO (1987): Derecho de propiedad y gestión privada de recursos de la naturaleza. Madrid. Unión Editorial.

- (2004): Estudios de Economía Política. Madrid. Unión Editorial. [2a edición]

- (2010): Socialismo, Cálculo económico y función empresarial. Madrid. Unión Editorial. [ $4^{\text {a }}$ edición]

JACOBS, J (2013): Muerte y Vida de Las Grandes Ciudades. Madrid. Capitán Swing. [ $3^{a}$ edición]

Menger, C. (1997): Principios de economía política. Madrid. Unión Editorial. [2 $2^{a}$ edición]

Martínez Meseguer, C. (2009): La teoría evolutiva de las instituciones. Madrid. Unión Editorial. [2 ${ }^{a}$ edición]

Mises, L. von (1920): Die Wirtschaftsrechnung im Sozialistischen Gemeinwesen

- (2002): Gobierno Omnipotente. Madrid, Unión Editorial.

- (2005): Burocracia. Madrid. Unión Editorial. [2a edición]

- (2007): La Acción Humana. Madrid. Unión Editorial.

- (2012): Planificación para la libertad. Madrid. Unión Editorial. 
MorRIS, A.E.J. (2007): Historia de la forma urbana. Barcelona. Gustavo Gili.

Ors, A. D. (2001): Derecho y sentido común. Madrid. Civitas. [3 ${ }^{\text {a }}$ edición] O’Sullivan, A. (2012): Urban Economics. Singapore. McGraw Hill International Edition.

Rothbard, M (1978): For a New Liberty, The Libertarian Manifesto.

Nueva York. MacMillan Publishing Co., Inc.

- (2008): La fijación general del precio de los factores de producción. Madrid. Unión Editorial.

- (2009): La ética de la libertad. Madrid. Unión Editorial. [2ª edición]

Zimmermann, C. (2012): La época de las metrópolis. Madrid. Alianza Editorial. 